The International Journal of Engineering and Science (IJES)

|| Volume || 6 || Issue || 6 || Pages || PP 78-81 || 2017 ||

ISSN (e): $2319-1813$ ISSN (p): $2319-1805$

\title{
Defluoridation of Ground Water Using Corn Cobs Powder
}

\author{
Lavanya $\mathrm{H} \mathrm{D}^{1}$, Madhushree $\mathrm{C}^{1}$, Vani $\mathrm{A}^{2}$, Manjula ${ }^{2}$ \\ ${ }^{I}$ Assistant Professor, Department of Civil Engineering, Rajeev Institute of Technology,Hassan, India \\ ${ }^{2}$ Assistant Professor, Department of Civil Engineering, Rajeev Institute of Technology,Hassan, India
}

\begin{abstract}
Most of the adsorbent used for removal of fluoride from drinking water is activated carbons. It is an expensive material, and so the use of alternative, which is a cheaper adsorbent, is required. Hence in the present work, an attempt has been made to remove the fluoride in drinking water using corn cobs powder as a natural adsorbent using a fabricated filter. The Bureau of Indian Standard has recommended the limit of fluoride content of $1 \mathrm{mg} / \mathrm{l}$ (BIS: 10500-2012). The water samples were collected in different places namely Uppinahally, Doddagatta and Yadapura in Arsikere taluk of Hassan district. The defluoridation is done with corn cobs powder and then the results were compared. Filtration with corn cobs powder reduces the fluoride content for the samples from Uppinahally, Doddagatta and Yadapura with initial fluoride content $2.5 \mathrm{mg} / \mathrm{l}, 1.2 \mathrm{mg} / \mathrm{l}$, and $1.4 \mathrm{mg} / \mathrm{l}$ respectively to $1.01 \mathrm{mg} / \mathrm{l}, 0.9 \mathrm{mg} / \mathrm{l}$ and $0.8 \mathrm{mg} / \mathrm{l}$ respectively.
\end{abstract}

Keywords: Corn cobs powder, Fluoride removal,

Date of Submission: 10 June 2017

$\longrightarrow$

Date of Accepted: 22 June 2017

\section{INTRODUCTION}

Groundwater is an important source of drinking water and it is estimated that more than 200 million people worldwide are drinking groundwater with fluoride concentrations greater than the WHO guideline value of $1.5 \mathrm{mg} / \mathrm{l}$. The majority of these cases occur in the developing world. Ground waters are much more vulnerable to fluoride enrichment than surface waters because of the greater impacts of water-rock reactions in aquifers.

Fluoride is one of the very few chemicals that have shown to cause significant effects in people through drinking water. Fluoride is found in all natural waters at some concentration. Sea water typically contains about $1 \mathrm{mg} / \mathrm{l}$ while rivers and lakes generally exhibit concentrations less than $0.5 \mathrm{mg} / \mathrm{l}$. In groundwater's, however, low or high concentrations of fluoride can occur, depending on the nature of the rocks and the occurrence of fluoride-bearing minerals. High fluoride concentrations may therefore be expected in groundwater's from calcium-poor aquifers and in areas where fluoride-bearing minerals are common. Fluoride with inadequacy causes dental carries, while if it is in excess amount $(>1 \mathrm{mg} / \mathrm{l})$ causes dental fluorosis and skeletal fluorosis which has no cure. Since fluorosis is an irreversible process, prevention of this is the only solution to protect against diseases. This can achieve by adopting defluoridation method by simple techniques.

\section{DEFLUORIDATION TECHNIQUES AND MATERIALS \\ DEFLUORIDATION TECHNIQUES}

Basically there are two methods for removal of excess amount of fluoride present in water, namely, flocculation and adsorption. Flocculation technique includes addition of chemical agents to precipitate the excess fluoride content present in water. In adsorption technique involves the adsorption of fluoride ions using activated agents such as activated alumina, activated carbon, bone char etc. Since these active agents are costlier, alternative adsorbents such as corn cobs, crushed tamarind seed, laterite soil, moringa olifera etc., can also be used. In this present study corn cob are used as adsorbing agent.

Materials Used

Corn Cob: Corn is a major crop plant, every part of which is utilized except cob. A corn cob is the central core of an ear of maize. It is the part of the ear on which kernels grow. The ear is also considered as a "cob" or "pole" but it is not fully a "pole" until the ear is shucked, or removed from the plant material around the ear. The inner most part of the cob is white and has a consistency similar to foam plastic. In this study an attempt is made to utilize this less- utilized plant part to clean one of the most precious natural resources, water.

Uses of corn cobs;

- Industrial source of the chemical furfural

- Fiber in fodder for ruminant livestock

- Bedding for animals- cobs absorbs moisture and provide a compliant surface

- Raw material for bowls of corn cob pipes 
Advantages of Corn cobs:

- Simple and Efficient

- Cost effective and Feasible

- Eco - friendly and locally available

- Porous and reusable

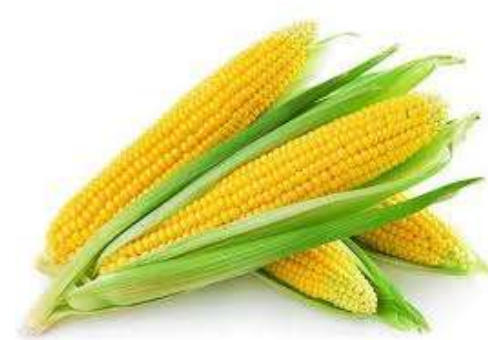

Fig 1(a)

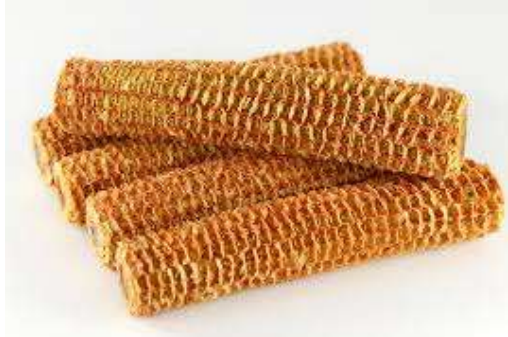

Fig 1(b)

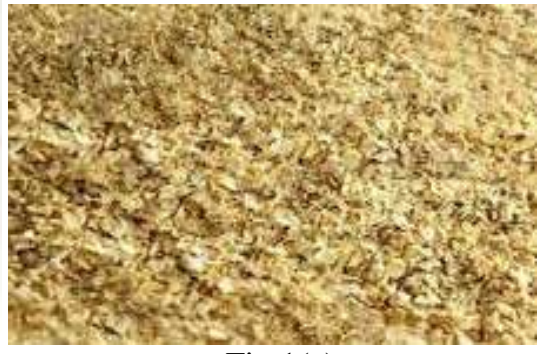

Fig 1(c)

Fig 1(a) (b) (c) shows corn, corn cobs, corn cobs powder

Sand: Sand is the loose granular material which is formed due to the disintegration of rocks. The composition of sand varies, depending on the local rock sources and conditions, but the most common constituent of sand in inland continental settings and non-tropical coastal settings is silica, usually in the form of quartz. The second most common type of sand is calcium carbonate.

Sand filters are mainly used for water purification for treating the raw water. While using sand as a filter media, two important things are to be kept in mind: sand grain size and sand bed depth.

Fabricated filter: the filter was fabricated as per requirement using locally available materials

- A stainless steel household filter was procured and fabricated as per requirements

- IS sieves of appropriate sizes are provided

- IS sieve of size 63 micron is provided at the primary course of filter media, in which micronized corn cobs powder is placed

III. METHODOLOGY

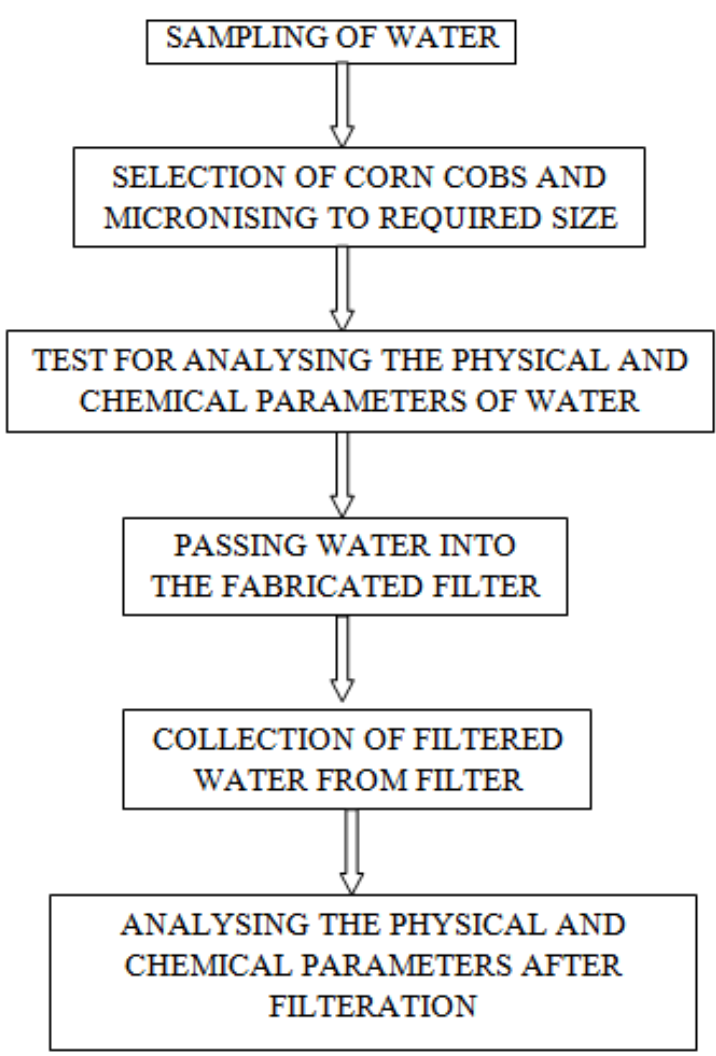




\section{Sampling from Arsikere Taluk:}

Water sampling and analysis involves the collection of water samples and measurement for chemical, physical and biological characteristics to determine its quality. According to the information given by the local people, samples from borewells of Arsikere Taluk were taken for the analysis. First sampling of about six liters of water was collected from Uppinahally, Doddagatta and Yadapura of Arsikere Taluk. Second sampling of about four liters of water was collected from each place mentioned above.

\section{Tests conducted on water samples:}

The water samples collected were analyzed in laboratory for the parameters such as fluorides, acidity, alkalinity, chlorides, dissolved oxygen, hardness, $\mathrm{pH}$, turbidity, electrical conductivity and total dissolved solids.

\section{RESULTS AND DISCUSSIONS}

The experiment was conducted with an aim to find the optimum removal of fluoride with corn cobs powder and the results are compared with Bureau of Indian Standards: 10500-2012. The physical and chemical parameters are tested before filtration. From the results we came to know that the three samples viz., Uppinahally, Doddagatta and Yadapura, fluoride content exceeded the desirable limit $(1 \mathrm{mg} / \mathrm{l})$ and hence treatment is required. Therefore the water samples were passed through corn cobs powder and the fluoride content has been reduced below $1 \mathrm{mg} / \mathrm{l}$ and hence it is safe for drinking.

Fig.2 shows that the fluoride content is above desirable limit for the samples before filtration which requires treatment. After the filtration process the fluoride content has decreased considerably. Fig. 3 shows that the acidic content in waster is within the limit. Hence no any treatment is required. High acidity in water may results in foul-tasting in water and low pH values generally have few health effects. Fig.4 shows that the alkalinity is within the limits for all the samples before and after filtration. Hence no further treatment is required for the samples. Fig.5 shows that the sample 1 has the chloride content more than the desirable limit, both before and after filtration. For sample 2 and 3, the content increased after the filtration. If the contents exceeds more than the limit, it can results in high blood pressure, salty taste, corroded pips, fixtures and appliances, blackening and pitting of stainless steel. Fig.6 shows that the hardness has exceeded the desirable limit for all the samples both before and after filtration. Fig.7 shows that the $\mathrm{pH}$ of all the three samples is within the limit. Hence no any further treatment is required and the samples are safe. Fig. 8 shows that the conductivity of all the three samples is within the limit. Hence no any further treatment is required and the samples are safe. Fig.9 shows that the TDS value is above the desirable limit. It can be removed by reverse osmosis or distillation. Fig. 10 shows that turbidity has increased after filtration. If it is increased over the limit, the water will be aesthetically unappealing, and promote growth of pathogens. This type of water can be treated by filtration process.

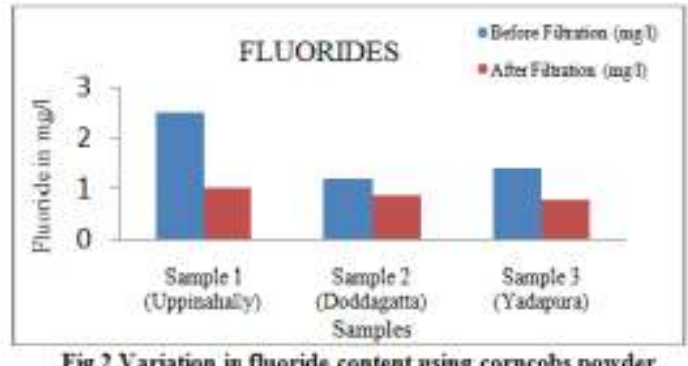

Fig.2 Variation in fluoride content asing corncobs powder

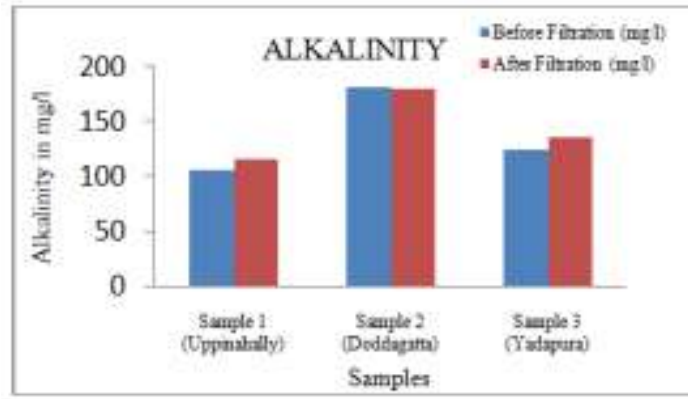

Fig.4 Variation in alkalinity using corncobs powder

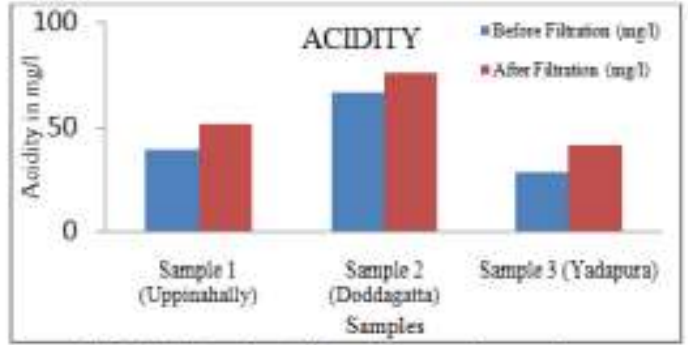

Fig-3 Variation in acidity using corncobs powder

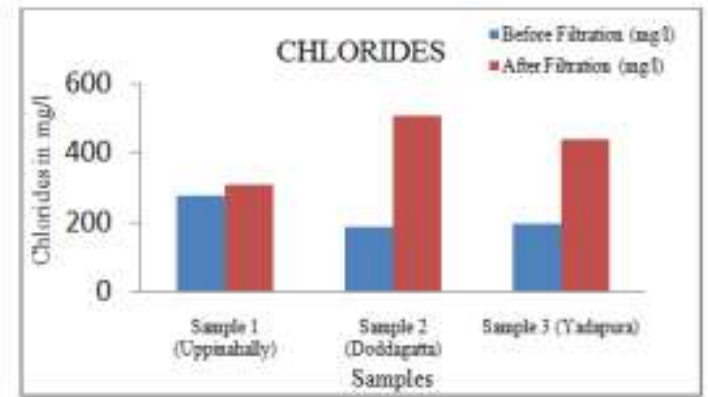

Fig.5 Variation in chlorides using corncobs powder 


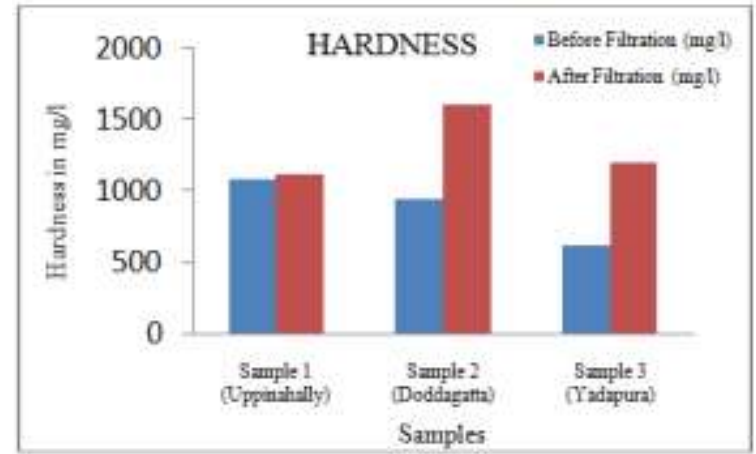

Fig.6 Variation in hardness using corncobs powder

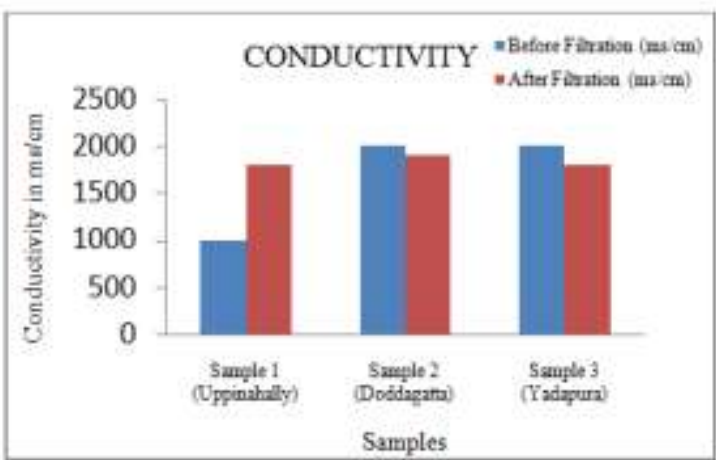

Fig.8 Variation in conductivity using corncobs powder

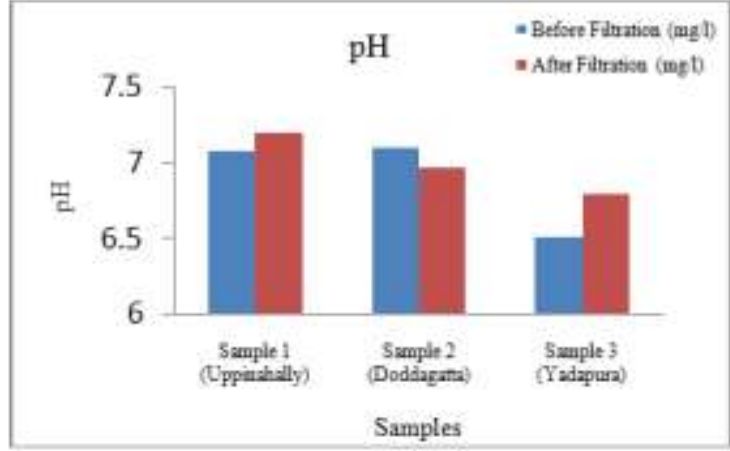

Fig.7 Variation in pH using corncobs powder

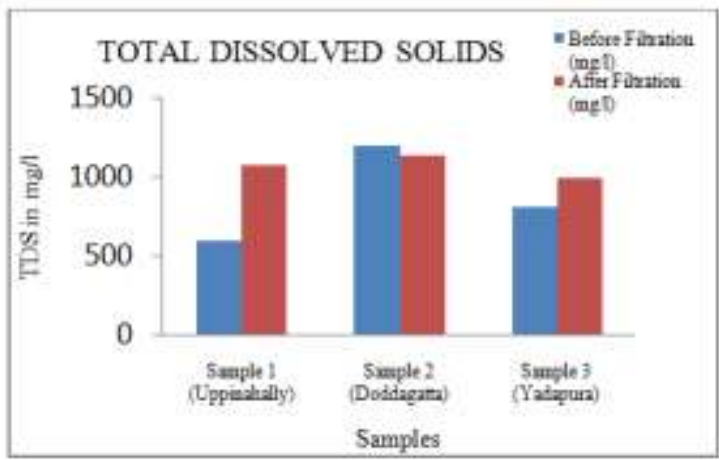

Fig. 9 V ariation in TDS using corncobs powder

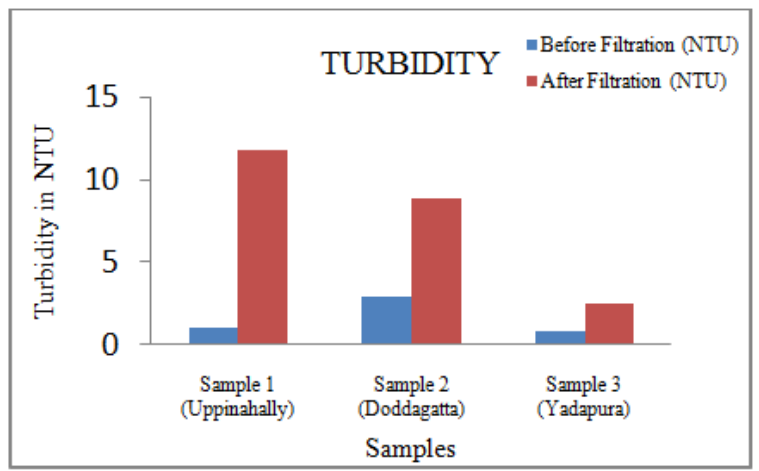

Fig.10 Variation in Turbidity using corncobs powder

\section{CONCLUSIONS}

The results show that the samples from Uppinahally, Doddagatta and Yadapur, have fluoride content more than the desirable limits, so it is processed under filtration to reduce fluoride content. Usage of corn cob powder efficiently reduced fluoride content; hence the natural low cost adsorbent can be used fruitfully for the removal of fluoride over wide range of concentration. The parameters like chlorides, hardness, and TDS has increased than the desirable limit which requires further treatments like distillation, softening, reverse osmosis etc for their further use as safe drinking purposes.

\section{REFERNCES}

[1]. Jadav A S and JADAV m v, (2014), " Use of maze husk fly ash as an adsorbent for the removal of fluoride from water", “ International Journal of Recent Development In Engineering And Technology" vol 2, pp:41-45

[2]. C M Vivek Vardhan and J Karthikeyan ,(2011), "Removal of Fluoride from Water Using Low Cost Materials", "15 $5^{\text {th }}$ International Water Technology Conference", pp:1-14

[3]. Hemant S. Parmar, Jignesh B. Patel, Padmaja Sudhakar and V.J. Koshy, (2006), "Removal of Fluoride from water with Powdered Corn Cobs", "Journal of Environmental Science and Engineering", vol 48(2), pp:135-138

[4]. T. Getachew, A. Hussen, V M . Rao (2015), "Defluoridation of water by activated carbon prepared from banana peel and coffee husk", "International of Environmental science and Technology", vol 12, pp: 1857-1866 